\title{
NIKLAS LUHMANN E RICHARD RORTY: CONTINGÊNCIAS E INCONSISTÊNCIAS
}

\author{
Edilene Maria Carvalho Leal ${ }^{1}$
}

\begin{abstract}
RESUMO: Rorty enfrentou as contingências do mundo contemporâneo apostando no partilhamento da "retórica das democracias liberais", como a mais aceita e mais adequada em uma sociedade caracterizada pelo fim das metanarrativas e das condutas de moral absoluta. Mas essa aposta resvala claramente num pragmatismo moral mal disfarçado. Luhmann, ao contrário, levou até o fim a preocupaçáo, abandonada por Rorty, de elaborar uma teoria antimetafísica e despida de um projeto normativo para a sociedade contemporânea. Sua teoria dos sistemas enfrenta as contingências do mundo, excluindo tudo que for externo ao sistema, ou seja, tudo que não possa se tornar um mecanismo de manutençấo da identidade dos sistemas face à complexidade do mundo.
\end{abstract}

PALAVRAS-CHAVE: Contingências. Complexidade. Utopia liberal.

\section{A DOMINAÇÁo Da IDENTIDADE}

O impulso inicial e a constituição sistemática do pensamento ocidental caracterizaram-se pela tentativa sempre recorrente de abandonar aspectos fundamentais da realidade e do pensar essa realidade. Desde Platão (1972, p.163), pensa-se a essência das coisas fora delas mesmas, habitando um mundo - o mundo das ideias - no qual o idêntico e o uno excluem qualquer sorte de contradição ou não-ser. Aristóteles (1969) debruça-se sobre o ser enquanto tal, mas categoriza os variados aspectos a partir dos quais a realidade se nos mostra, em substância e acidentes, de forma que o tempo e o movimentar-se das coisas (do ser) seriam apenas acidentes (ou atributos) que não alterariam a identidade da coisa em si mesma. Em ambas as filosofias, e nas mais diversas variantes que delas decorrerem, na tradição metafísica ocidental, preconizouse o pensamento da identidade ${ }^{2}$ e da essência com base na qual se ordenam os

\footnotetext{
${ }^{1}$ Doutora em Sociologia pela Universidade Federal de Sergipe; membro do Grupo de Pesquisa Sociedade e Técnica (SOCITEC/NPPS/UFS); Professora de Filosofia e Sociologia. Área de interesse: Teoria Social e Filosofia moderna e contemporânea. Endereço: Rua Tenente Antônio Fontes Pitanga, no 256. Cond. Vitta Clube, ed. Esperanza, apto 1301. Bairro: Farolândia. CEP. $49032-$ 360. Aracaju-SE. E-mail: edileneleal@gmail.com

${ }^{2}$ Referindo-se ao problema da identidade na história do pensamento ocidental, escreve Luhmann:

"No sistema clássico da metafísica ontológica se introduz o esquema binário da lógica para separar
} 
acidentes, as contingências e as contradições. Isso significa dizer que a tradição teve clara percepção de que existe o não-ser, porém, concebeu como sua tarefa precípua livrar-se da sua presença desestabilizadora e descentralizadora, para que sobrevenha a ideia, a identidade, Deus, a razão, o sujeito transcendental, o espírito absoluto.

A contingência, a diferença, a autopoiesis, entretanto, foram despertas de seu sono dogmático pelos mais diversos - no tempo e no espaço do ocidente moderno - pensadores da crítica da metafísica e da razão iluminista, os quais, dentre outras tantas açóes teóricas, suprimiram quaisquer fundamentos de estabilidade e universalidade que preexistam ao homem e à sua sociedade, a saber: uma natureza humana comum que responda pela possibilidade de comunidade política; uma instância psicológica superior (a consciência) e ordenadora das confusốes dos instintos; uma razão propiciadora de conhecimento verdadeiro e universal. Ao invés dessas figuras da tradição, pensadores mais atuais, como Nietzsche (1998), Heidegger (1971; 1986), Derrida (2006; 2002), Luhmann (1997), Foucault (2002), Deleuze (2006), pensam as extremidades da diferença e da contingência e enfrentam decididamente a finitude do homem e de seu mundo: todos têm em comum, portanto, a recusa da ideia de totalidade e de completude. Contudo, cada um deles encerra o seu predecessor (pensador com quem dialoga) nos rasgos essenciais da metafísica, acusando-o de "metafísico disfarçado"3, tal como a vontade de potência nietzscheana, que se "ontoteologiza" em Heidegger, com seu Sein que não experimenta plenamente a desconstrução e a différance em Derrida, as quais encontram limites lógicos na lúcida percepção de Luhmann ${ }^{4}$ de que náo se pode desconstruir sem, ao mesmo tempo, construir alguma coisa, sem criar estruturas, sem pressupor unidade.

e enlaçar ser e pensamento. Por um lado, o pensar, no nível da formulação linguística, possibilita a distância, a diferença e a contradição; por outro lado, a lógica funciona ao possibilitar a identidade, para extirpar o que no pensamento se desvia do ser. O pensamento se torna consciente a si mesmo como consciência e se caracteriza a si mesmo na medida em que se distancia do ser como não-ser, como erro, como engano" (1998, p.110).

3 "Quando o indivíduo conclui que descobriu um modo de se tornar muito diferente desses predecessores, de fazer algo muito diferente do que eles fizeram, sofre o que Heidegger chamou de "recaída na metafísica”" (RORTY, 2007, p.186).

4 "As diferenças que orientam tais semânticas (acima/abaixo, antes/depois) pressupóem, contudo, o mundo como unidade da diferença, são estáveis na medida em que são capazes de responder às estruturas e às experiências que de fato decidem o resultado da situação histórica do sistema social" (LUHMANN, 1997, p.85, grifo no original). 
Disputas de titãs à parte, somos incitados a pressupor que até mesmo as tentativas mais contemporâneas de pensar fora do leito de Procusto da identidade, da ordem pré-estabelecida e da essência esbarram em dificuldades, principalmente aquela de se ter como segura a efetiva construção de uma teoria científica ou filosófica que tenha de fato enfrentado, de modo consequente, as velhas figuras da tradição metafísica. De fato, se pensarmos, com Derrida (2002), que um texto tenha ampla independência de seu autor e aquilo que supostamente este quis dizer não tem valor determinante em sua compreensão, é possível sustentar que algumas teorias contemporâneas (independentemente do que se segue ao pós) fora de seus esquemas conceituais internos, isto é, comparados com outros esquemas ou a partir de um conjunto de critérios externos (GRANGER, 1989), produzem inconsistências lógicas e epistemológicas que resultam, inclusive, da permanência de resquícios ainda significativos de metafísica. Isso não seria exatamente um problema, se alguns desses pensadores não se autodenominassem antimetafísicos por excelência e não pressupusessem essa condição, ser antimetafísico, para a atividade científica e filosófica comprometida com uma postura epistemológica desestabilizadora, descentralizadora, desconstrutivista, superadora.

A partir de Heidegger 5 , pensadores como Derrida, Deleuze, Foucault e também Luhmann encaminham suas construçóes teóricas tendo por base a tarefa de crítica e destruição da metafísica ocidental. Pensar a diferença, a contingência, o ser, o não-ser, a complexidade, enfim, parece pressupor, em níveis distintos, uma intensificação do que Hegel chamou de consciência dilacerada de si, aos olhos da qual as determinaçóes fixas, identitárias e universais da modernidade são problematizadas. Com esses pensadores, estamos diante da experiência de inversão irônica da realidade tomada em seus fundamentos últimos e da experiência de radicalização do não-ser e do não-racional. Todavia, esses pensadores que vivem sob a égide de uma conduta irônica ou que são ironistas em sentido rortyano, são presas mais ou menos fáceis das armadilhas criadas por sua condição de teoristas que, segundo Rorty, os implica em uma certa tendência em "pensar em coisas grandes": o destino do Ser, da Europa, da Vontade de Potência, da Complexidade do Mundo. Isso parece significar que o limite das teorias ironistas, na acepçáo de Rorty, é interno a elas mesmas, ou seja, as recriaçôes teóricas não resistem à sedução da grande narrativa - sedução à qual os romancistas, os poetas e os jornalistas do

${ }^{5}$ Afirma Gerd Bornheim: "Portanto, o pensador maior do tema da diferença é, sem dúvida, o já clássico Heidegger. A expressão consagrada é 'diferença ontológica', que abre espaço para pensar a separaçăo entre ser e ente" (1996, p.107). 
paradigma estético rortyano são aparentemente imunes. Mas não ele próprio, isto é, Rorty, é um desses teóricos ironistas que se rendem diante da "vontade" de recriar uma coisa grande: a utopia e solidariedade liberal.

\section{NiKLAS LUHMANN E A PRESSÃO DA COMPLEXIDADE DO MUNDO}

Niklas Luhmann apresenta como o problema por excelência das ciências - e da sociologia em especial - aquele da complexidade do mundo, em que estar no mundo é, permanentemente, fazer face à pressão da complexidade e de modo algum dar conta de resolvê-lo definitivamente, em qualquer versão metafísica. Quando define, dessa maneira, seu problema, questiona e até mesmo subverte as bases de todo o pensamento que Aristóteles tanto contribuiu para fundar. $\mathrm{O}$ mundo - concebido na teoria dos sistemas (LUHMANN, 1998, p.13) como ambiente ou entorno - não é dado como objeto para ser descoberto ou deduzido ou construído por um observador exterior que o organiza em sua suposta identidade e universalidade, como um Deus leibniziano ou uma subjetividade pensante ou um sujeito transcendental ou, ainda, uma fenomenologia eidética. Sua teoria dos sistemas opera por meio de uma crítica impiedosa a todas essas tentativas metafísicas de compreender a sociedade, porém, não se limita a, meramente, "superar" ou "desconstruir", seja qual for o verbo pós-moderno usado para efetuar a crítica da tradição e das ilusóes metafísico-modernas. Luhmann - que facilmente pode ser localizado em um grupo de pensadores epistemológicos e socialmente construtivistas parece preocupado em construir uma teoria que dê conta do estabelecimento de outros parâmetros para a ciência sociológica, concernentes ao caráter complexo e contingente tanto da sociedade quanto do observador hodierno.

Luhmann pretende abandonar definitivamente o terreno das essencialidades metafísicas e da filosofia do sujeito e, para isso, constrói uma teoria dos sistemas segundo a qual estabelecer conceituaçóes e análises somente é possível por meio das diferenças. Sendo assim, definir interaçôes, sociedades e organizaçôes, em uma palavra, a saber, sistemas, é pensar suas diferenças operacionais em relação ao seu ambiente.

Como um sistema constrói a si mesmo como sistema? Efetuando operaçóes próprias com operaçôes próprias e diferenciando-se, assim, em relação a seu ambiente. A continuação das operaçôes do sistema é a reprodução de si mesmo e, por sua vez, a reprodução da diferença entre sistema e ambiente. (LUHMANN, 1998, p.14). 
Essa perspectiva de análise sociológica inaugura um verdadeiro corte epistemológico ${ }^{6}$ na sociologia e nas ciências humanas, de forma geral, uma vez que a sociedade apareceu, para as mais variadas teorias sociais, como objeto que, embora pressupusesse mudanças configurativas, ainda assim era dado em sua unidade e universalidade para ser conhecido. A crítica de Luhmann é endereçada a todo pensamento sociológico que o antecede - quer a teoria estrutural-funcionalista de Parsons ${ }^{7}$, a qual pressupóe a totalidade quase imutável do social, quer as teorias da açáo de Weber a Habermas, respectivamente, que remetem o social para a ação individual ou para o ontológico mundo da vida. Para Luhmann, a sociologia se comporta com a sociedade como se esta fosse o "sujeito" autorreferencial de suas estruturas e construçóes. Os sistemas sociais se constituem enquanto estabelecem suas fronteiras distintivas no mundo que lhe serve de ambiente, o que significa que os sistemas, sejam físicos, sejam sociais ou psíquicos, se autoconstroem (autopoiesis) e definem sua "identidade" mediante sua diferença com o que está fora deles. Cada operação que se efetiva, e no caso do sistema social, cada comunicação realizada, gera limites fronteiriços que novamente adentram em uma rede de operaçóes futuras. De acordo com Luhmann, as mais variadas teorias sociológicas são apenas matizes de uma mesma teoria, a teoria da ação, cuja característica fundamental é a ligação indissolúvel com certo humanismo. Isto é, traduz a substituição do continuum entre Deus

${ }^{6}$ Luhmann parece ter plena consciência disso, quando escreve: "Ao aceitar isto, se renuncia a premissa de que a consciência é o sujeito do mundo. A duplicação empírico-transcendental dos fatos da consciência deixa de ser necessária. Todavia se pode dizer, se se quer salvar a terminologia do sujeito, que uma consciência é um sujeito do mundo, ao lado do qual existem outros sujeitos, sobretudo os sistemas sociais, que os sistemas psíquicos e sociais são os sujeitos do mundo, que a auto-referência significativa é o sujeito do mundo e que o mundo é um correlato do sentido. De qualquer maneira, tais teses rompem a tese da diferenciação cartesiana entre sujeito e objeto" (1998, p.391).

${ }^{7}$ Percebe-se, claramente, por que Luhmann se afasta da teoria estrutural-funcionalista de Parsons. Para este último, os sistemas sociais são estruturados de forma que as realizaçóes funcionais existem para a manutenção dos sistemas. Qualquer anomia ou contingência será imediatamente absorvida pelas operaçōes funcionais internas que as integram e mantêm a integração sistêmica. Mesmo quando tematiza o problema da "dupla contingência da interação", no subsistema da personalidade, para o qual os atores sociais podem dar respostas criativas e, portanto, diferentes, Parsons recorre aos padrốes culturais normativos como fator fundamental de bloqueio do conflito e da mudança nos sistemas sociais. A crítica de Luhmann ao estruturalismo-funcional é direta: o enfoque na estrutura, a expensas da funçáo, incorre na impossibilidade de "[...] problematizar o sentido da formação estrutural" (LUHMANN, 2005, p.74), como se fosse uma totalidade permanente e indiferenciada; todavia, a inversão do par conceitual em funcionalismo-estrutural é decisiva para uma correta compreensão dos sistemas sociais e para o questionamento da "função das estruturas sistêmicas" (idem) no mundo. Pensadas em termos primordiais de funçôes que se diferenciam, mudam e transmutam constante e infinitamente, engendram estruturas sistêmicas que se autoproduzem, de modo a reduzir o excedente de semantização. Isso significa afirmar que se coloca para a teoria dos sistemas de Luhmann a tematizaçăo da diferença e da contingência. 
e o mundo por aquele entre a razáo humana e o mundo. Nesse continuum, ressaltam-se as ações humanas, aquelas que seriam responsáveis pela feitura dos sistemas sociais, sem as quais não seria possível também sua evolução. Com isso, o caráter central dos sistemas é o ser humano, que deve submeter todos os âmbitos societários à satisfação de suas preferências valorativas diversas e de seus anseios igualmente variados de emancipação ${ }^{8}$, mesmo porque essa ação não é uma ação humana qualquer, mas aquela que pode, sempre que quiser, atualizar seu potencial racional no controle das forças da natureza, dos ordenamentos sociais, que ele próprio constituiu, da demarcação de sua esfera de atuação, do destino generalizado mediante consensos pré-definidos etc. Ou seja, o continuum da modernidade movimenta-se tanto a partir da vontade de verdade quanto da vontade de poder: sabe-se limitado, mas, mesmo assim, enseja o poder sobre todas as coisas.

Compreender a modernidade e seus autores com base na perspectiva da racionalidade não é, em si mesmo, um procedimento científico novo. Vimos que essa se constitui em diretriz central para enaltecer seus feitos e para destacar seus fardos e seus excessos. O que se apresenta de maneira nova, na teoria luhmanniana, seria o método de análise e as conclusóes retiradas dessa análise, pois, quando nos voltamos para as pesquisas de Spencer Brow (LUHMANN, 2009, p.86), podemos lembrar que a operação da observação pressupóe o uso da diferença para definir um do lado e não o outro, daquilo que é observado. Contudo, ao lado que é definido ou indicado não se chega de um só golpe, isto é, demanda uma série de operaçóes recursivas a partir das quais se pode chegar a um resultado impossível de ser descartado. A fim de que se realize, por conseguinte, a operação da observação (ou seja, da diferenciação), é necessário que exista um sistema autoconstitutivo ou autopoiético atuante, para processar a comunicação da observação. A observação demanda, por conseguinte, tempo entre o que foi e o que será observado: o antes e o depois já consistem em uma diferença. Ora, o observador náo tem poderes divinos para estar em dois pontos temporais simultaneamente: ou ele vê um lado ou vê o outro lado da diferença, porquanto, na teoria da observaçáo permanece uma assimetria de base, uma vez que o observador apenas maneja um dos lados da diferença, vendo o outro lado apenas de relance; quando se situa num "ponto fixo", toda a observação é operacionalizada a partir dele e não de outro. É esse ponto fixo que confere unidade à operação de observação,

\footnotetext{
8 "As construçóes baseadas em ideais (emancipação, conceito normativo de racionalidade) assumem tão
} somente um papel quando se trata de "suspender" (aufheben) a diferença" (LUHMANN, 2007, p.21). 
ao qual Luhmann (2009, p.158), referindo-se a Spencer-Brown, chama de "ponto cego da unidade de operação do observar".

Essa difference that makes a difference (Luhmann, 2009, p.83; 2007, p.61) tem amplas consequências para as observaçóes científicas sobre a sociedade. Destacaremos três: a primeira - do lado do qual o sociólogo parte, a sociedade - implica que se assuma a diferença basal entre sistema/ambiente. A segunda supóe a existência de vários sistemas sociais, que se diferenciam entre si (subsistemas político, econômico, educacional, científico etc.) e se distinguem das máquinas, dos organismos e dos sistemas psíquicos, uma vez que se caracterizam por processos autorreferenciais e autopoiéticos, irredutíveis uns aos outros. O que nos interessa, aqui, é a exclusão recíproca entre sistemas sociais (operam com comunicação) e sistemas psíquicos (operam com a consciência); ainda que ambos trabalhem com a produção de sentido, fazemno com base em operaçóes autológicas, isto é, os sistemas sociais não podem condicionar o fluxo do pensamento e tampouco os sistemas psíquicos podem determinar as estruturas comunicacionais que circulam na sociedade. A diferença entre indivíduo e sociedade (LUHMANN, 2007, p.63) se estabelece em torno da exclusão recíproca: a sociedade não se ocupa e nem é ocupada por seres humanos, e o indivíduo movimenta-se a partir de operaçóes próprias, inclusive a que possibilita a observação externa da sociedade. Em Introdução à Teoria dos Sistemas, Luhmann dá-nos indicaçôes claras sobre isso:

Evidentemente, somos observadores externos da sociedade: reconhecemonos fazendo parte de uma vida social já constituída, que paga aos pensionistas, ou na qual temos lido livros que nós mesmos teríamos querido e podido escrever. Contudo, náo podemos nos ocupar da sociedade, na qualidade de sociólogos, como se esta pudesse ser observada externamente. Os sistemas de consciência podem, indubitavelmente, observar a sociedade a partir de fora; mas, socialmente, isso fica sem efeito, quando não se comunica; ou seja, se a observação não é realizada dentro do sistema da sociedade. (LUHMANN, 2009, p.99).

Com a prerrogativa de que não existem seres humanos no lado da forma sociedade, Luhmann pretendeu pôr por terra dois dos principais avatares da tradição de pensamento social: a teoria da ação social e a filosofia do sujeito (LUHMANN, 1998). Na medida em que essa tradição recusou a diferença sistema/ambiente, não pôde formular, de acordo com Luhmann, 
uma concepção sociologicamente adequada de sociedade. Toda tradição ${ }^{9}$ assumiu a perspectiva ontologizante e analítica da sociedade, que viabiliza ao sujeito adentrar no sistema social, integrando-o e definindo-o conforme seus interesses e vontade, visto que é factível ao sujeito operar transformações sobre a sociedade, não apenas porque o faria por meio de uma observação de fora (LUHMANN, 2007, p.110), mas, primordialmente, porque é um sujeito capaz de ação racional ${ }^{10}$. Contra essa visão racionalizante e humanista de sociedade que define uma identidade universal e universalizante, Luhmann ${ }^{11}$ advoga que, enquanto cientistas, esses pensadores, tais como ele, somente podem se posicionar do lado da observação de segunda ordem, ou seja, sempre observam observaçôes, porque sempre chegam tarde às situaçôes, às açóes e aos acontecimentos primevos. Por isso, a ciência opera a observação da sociedade no interior da própria sociedade, não é uma observação externa.

Essa assertiva luhmanniana parece ficar entre posiçóes que, tradicionalmente, se excluem mutuamente: positivismo e relativismo. De fato, pode-se perguntar a partir do que foi frisado acima: será que, fora das salas de aula e de seu escritório de cientista, Luhmann posicionou-se do lado do ambiente enquanto sistema de consciência? Trata-se de uma questão inócua, porém, não sem importância, pois recoloca o velho problema do positivismo - tanto aquele deslindado por Comte, no século XIX, quanto aquele imiscuído nas reviravoltas do positivismo lógico e da filosofia analítica do século XX -, segundo o qual o cientista se mantém neutro e distanciado

${ }^{9}$ Parsons, inclusive, assume que a condição para a integraçáo social depende da estrutura de um consenso de valores que estaria na base da cultura. Ver, para tanto: La Estructura de la acción social, 1968.

${ }^{10}$ Segundo Luhmann, a modernidade se auto-observou e se autodescreveu a partir da racionalidade. Porém, se esta for entendida como atributo exclusivo do ser humano, também não faz parte do sistema societal, mas do lado da forma sistema psíquico. Temos, então, que: ação social e racionalidade são elementos de um mesmo lado em relação ao outro lado da forma, a sociedade. Enquanto tais, evidentemente, mantêm uma relação de mútua importância um para o outro, na medida em que compartilham a funçáo de produzir sentidos (possibilidades de ação e de comunicação), na medida em que, para marcarem uma diferença, pressupóem o outro como o lugar não-marcado (relação de interdependência), bem como na medida em que articulam uma relação dialética sem síntese possível, entre reação a ordem normativa e afirmação da ordem normativa; porque são ambientes um para outro. Apenas ecos, ruídos, irritaçóes, provindos do ambiente (dos sistemas psíquicos) podem ou não ser selecionados e integrados na ordem social. De qualquer forma, o mecanismo que operaria com esses elementos não é da alçada da consciência, mas da comunicação; assim como o processo que o embala, o processo evolutivo, náo pressupóe nenhuma lógica racional que lhe seja externa.

11 "Portanto, partimos de uma descrição fenomenológica de experiências de sentido e de nexo constitutivo sentido/entorno, porém náo fundamos essa descrição na pré-existência de um sujeito extramundano (que todos sabem que existe como consciência), mas a concebemos como uma descrição do mundo no mundo" (LUHMANN, 1998, p.86). 
de seu objeto de pesquisa, a fim de mais adequadamente apreendê-lo e validar seu conhecimento.

Embora se possa dizer que Luhmann resolveu, em parte, essa dificuldade, uma vez que fez desaparecer a relação sujeito/objeto ${ }^{12}$ do universo teórico da sociologia, mediante a premissa da diferença, pode-se, ainda assim, pressupor que sua solução o inclui em outro problema: o do relativismo da teoria. Em linhas gerais, seu esquema de conhecimento procede da seguinte maneira: o ato de conhecer revela-se enquanto ato de observar; este, por sua vez, se estriba sobre os esquemas de distinçôes (as formas) que não foram criadas por um deus ex machina e tampouco por sujeitos racionais, mas por sistemas produtores de sentido. O sentido, a partir do momento em que é selecionado em face de todas as outras possibilidades, deixa de ser pensamento de um sistema psíquico e tornase uma comunicação social passível de ser observada pela observação de segunda ordem: não é da ordem do particular, mas da ordem do compartilhamento social, um estar aí à disposição. Nesse tipo de observação, é possível que um sistema social, a ciência sociológica, observe as autodescriçôes que a sociedade produz de si mesma, sendo que ele próprio é um fenômeno social como outro qualquer, o qual opera por meio de esquemas de distinçôes e ocupa um dos lados da forma. Por conseguinte, não faz sentido falar em termos de sujeito/objeto, porque essa distinção é substituída pela distinção interna aos próprios sistemas pela distinção sistema/ambiente. Porém, se se observar com base na seleção de um dos lados da forma, o outro lado não foi considerado, ainda que mantivesse a mesma estatura de possibilidade de observação. Como evitar a recusa pós-moderna das "pretensôes universalistas da racionalidade" que resvalou no pragmatismo, relativismo, multiculturalismo, historicismo? Luhmann responde diretamente a essa questấo:

Porém, quando todo observar se vê obrigado a dissolver seu próprio paradoxo, sem dá razóes idôneas (inocentes) para isso, os teoremas da incompletude em todas as suas formas perdem o desejo de permanecerem pequenos diante do que seria desejável. De agora em diante, deve-se partir da universalidade da coação de selecionar, da universalidade do distinguir, do estabelecer limites; e se existe razão para não se reconhecer isso corre o perigo de permanecer associada a uma lógica totalitária ou até mesmo terrorista. (LUHMANN, 2007, p.143).

${ }^{12}$ Essa questão não faz sentido para a sociologia luhmaniana, porque, primeiro, não existem sujeitos no sistema sociedade; segundo, a comunicação se oferece como substituiçẫo dessa relação, mantendo-se aquém e além dela; enfim, o substrato dessas características da teoria sistêmica: quando a racionalidade perde seu horizonte de atuação nas sociedades, implica o desaparecimento da separação entre sujeito/objeto. 
Essa maneira enfática e dramática assumida nesse escrito de Luhmann diz muito sobre o que significa um de seus paradoxos preferidos, a unidade da diferença. Lembremos: o que caracteriza as sociedades contemporâneas é a complexidade. Todavia, o que significa essa complexidade? Significa, primeiro, que o entorno dos sistemas é constituído por acontecimentos permanentemente abertos à dimensão do tempo, que nada mais é do que a dimensão do possível; segundo, pela experiência igualmente aberta do sentido ou da semantizaçáo; tudo isso acrescido do fato de que as sociedades contemporâneas são caracterizadas pela profusão de informação, associada ao desenvolvimento da técnica de elaboração e difusão da informação a pleno vapor, na atualidade, com a internet. Assim, a alta complexidade do mundo se apresenta em dois níveis de problemas distintos, que são, respectivamente, o nível filosófico e o nível sociológico, visível no cotidiano das pessoas. A questão que se coloca é: como Luhmann tenta resolver o problema da alta complexidade produzida pelo ambiente dos sistemas, bem como pelos próprios sistemas, psíquicos e comunicacionais?

Luhmann parte da fenomenologia de Husserl, especialmente de sua concepção de que o mundo é caracterizado, de ponta a ponta, por sentidos diversos, visto que cada sentido que está aí remete a outros sentidos os quais remetem a outros, e assim por diante. Daí o porquê da complexidade do mundo. Husserl encontra unidade ou fundamento último para essa profusão infinita de sentidos na ideia de mundo da vida (Lebenswelt), ou seja, na ideia de que os sentidos dispersos e múltiplos encontram sua unidade no compartilhamento de padrôes normativos, científicos, culturais e éticos apreendidos e elaborados pelos seres humanos, ao longo de sua história. Esse mundo da vida se oferece, dessa forma, na perspectiva husserliana, como horizonte de sentido, como o redutor de complexidade. Porém, ainda que Luhmann, de um lado, aceite de bom grado o conceito sobre o ambiente e seus sistemas - em Husserl, mundo -, como carregado de sentidos, porque se definem e existem no plano temporal e contingente, invariavelmente mutável, não planejado, efeito de acasos e da produção e difusão constante de conhecimento, de outro, recusa a concepção husserliana de mundo, da vida como fundamento último, porque, para ele, o que confere unidade à diversidade de acontecimentos e remissóes de sentido é o ambiente como locus da diferença ou como o encontro das diferenças. Com efeito, o ambiente é uma sucessão infinitamente aberta de contingências, ao passo que os sistemas, os quais fornecem alguma unidade, apenas promovem a seleção dos possíveis, isto é, daquilo que é assim, mas 
poderia ser, e necessariamente ${ }^{13}$ será, de quaisquer outros modos. $\mathrm{O}$ ambiente funciona como "[...] o fundamento do sistema, e o fundamento é sempre sem forma” (LUHMANN, 1998, p.396, grifo no original) ${ }^{14}$.

$\mathrm{Na}$ ótica de um pensamento desontologizado ${ }^{15}$ e contingente, os sistemas sociais e os sistemas psíquicos dotam o mundo de ponta a ponta de sentido, na medida em que cada experiência no mundo remete, invariavelmente, aos conteúdos de outras experiências que já aconteceram ou que acontecerão: mistura-se nessa experiência atual uma variedade de possibilidades de sentido, em que umas são centrais e outras tantas marginais como horizonte de referência ${ }^{16}$. Os sistemas assumem uma ampla liberdade frente ao tempo, porque cada acontecimento desencadeado modifica o tempo, na medida em que se refere à diferença determinante entre o antes e o depois - uma ação presente mobiliza sua diferença com o passado e com expectativas futuras. Vale a pena conferir uma passagem extensa dos "Sistemas Sociais", mas esclarecedora dessa relação entre tempo e sistemas:

Cada acontecimento muda totalmente o passado, o futuro e o presente - pelo simples fato de outorgar a qualidade de presente ao seguinte acontecimento e de converter-se para este (isto é, o futuro) em passado. Por meio dessa transformação mínima pode mudar também o ponto de vista relevante que estrutura e limita os horizontes do passado e do futuro. Cada acontecimento realiza neste sentido uma modificação total do tempo. A pontualização temporal dos elementos como acontecimentos somente é possivel no tempo e graças ao tempo; porém realiza mediante o desaparecimento e a modificaçáo total um máximo de liberdade frente ao tempo. Esta liberdade adquirida se paga com a formação de estrutura, porque se torna necessário regular a reprodução dos acontecimentos por meio de acontecimentos. (LUHMANN, 1998, p.263).

${ }^{13}$ Escreve Luhmann: "A necessidade não é necessária devido a uma causa, nem a uma lei. A necessidade não é outra coisa que a mesma reprodução autopoiética. Esta necessidade de reprodução autopoiética tem frente a si mesma apenas uma alternativa: a finalização, a conclusão do sistema. Neste sentido, toda ordem tem uma direçáo antiteleológica. Precisamente o que não se quer é esta conclusăo!" (1998, p.267 - grifo do autor).

14 "A peculiaridade do ambiente do homem de remeter para o infinito e, no entanto, de atuar com doação de sentido e de um modo finito, tentou Husserl captá-la na imagem do 'horizonte'. Contudo, essa metáfora táo pertinente não foi de grande ajuda para a análise funcional" (LUHMANN, 2005, p.76).

15 Salienta Luhmann: "O conceito de complexidade designa sempre uma relaçâo entre sistema e mundo, nunca um estado do ser" (2005, p.77).

16 "O fenômeno do sentido aparece sob a forma de um excedente de referências a outras possibilidades de experiência e ação. Algo está no foco, no centro da intenção, e outro está indicado marginalmente como horizonte da atual e sucessiva experiência e ação" (LUHMANN, 1998, p.78). 
Náo deixa de ser surpreendente uma análise que trate de estruturas e de sistemas radicalizar de forma tão profunda a contingência e o tempo, desestabilizando os fundamentos da imutabilidade e da identidade das metafísicas clássicas e modernas. E é justamente essa experiência de radicalização que nos remete rapidamente às alusões temporais de Em Busca do Tempo Perdido, às quais o acontecimento sumamente presente comparece como figura de reminiscência, de distância e de retenção do passado e do futuro. Dessa obra romanesca, um fato dos mais célebres e citados por comentadores da La Recherche, átomos de tempo, é aquele em que o narrador, em uma situação do cotidiano, mergulha uma madeleine numa xícara de chá e atualiza suas impressões da sua infância em Combray; essa atualização é reveladora da ação presente, que redescobre o passado com suas impressôes atuais, as quais, de algum modo, servirão de conteúdos remissivos aos acontecimentos futuros.

Isso acontece porque, para Proust, o tempo é fluido e efêmero, as experiências vividas são contingenciadas ${ }^{17}$ pela possibilidade determinante de que o tempo as modifique continuadamente e de que remeta a outras experiências que as aniquilam. Parece-me emblemático disso, primeiro, o acontecimento da morte da avó do Narrador que, no presente vivido, foi-lhe indiferente, mas que a memória involuntária recobre o acontecimento de um profundo e doloroso sentimento de perda. O Narrador proustiano narra do seguinte modo suas impressóes: "Então, passou-se de maneira inversa a mesma coisa que com relaçáo a minha avó: ao saber que ela morrera, a princípio não senti o menor desgosto. Não sofri efetivamente com a sua morte, senão quando lembranças involuntárias a tornaram viva para mim" (PROUST, 1988a, p.208). O segundo também é revelador dessa aproximação e distinção do tempo perdido e do tempo redescoberto e do caráter absolutamente transitório e contingente do tempo em que uma situaçáo demanda sua aniquilação, reminiscências de um tempo que somente pode ser vivido na sua antiteleologia e na sua ausência de permanência e transcendência. Tratase do momento no qual o Narrador descobre-se apaixonado por Albertine: "Sentia que minha vida com Albertine não era, de minha parte, quando eu não tinha ciúmes, senão aborrecimento, e por outro lado, quando não os tinha, senão sofrimento" (PROUST, 1988b, p.338). O outro lado do amor é seu aniquilamento, o ciúme, da posse a perda, da vida a morte. Esse tempo proustiano somente encontra algum nível de organização e regularidade na

17 "A idéia de sua unicidade não era mais um a priori metafísico tirado ao que Albertine possuía de individual, [...] Mas um a posteriori constituído pela imbricação contingente e indissolúvel de minhas lembranças" (PROUST, 1988a, p.127). 
tarefa heroica de seu herói às avessas, o Narrador, que na profusão de memórias involuntárias que lhe afloram nas inúmeras experiências e remissóes, significa sua experiência na estrutura da duração do tempo; diga-se de passagem, apenas esta permanece: a duraçáo do tempo.

Tal como o Narrador do tempo perdido e do tempo redescoberto, o Narrador benjaminiano da história parte de uma perspectiva aberta e contingente do tempo, na medida em que existe uma relação inseparável do passado e o presente, mediante um "agora” que faz, involuntariamente, vir à tona acontecimentos esquecidos do passado: o famoso salto de tigre do agora em relação ao passado. A escritura de Benjamim, como todos sabem, é imagética, por isso ele traduz esse conceito de tempo na imagem deixada pela consciência da Revoluçáo de Julho, na qual o fim de um dia de combate terminou com trabalhadores em diferentes pontos de Paris, concomitantemente e sem planejamento prévio, disparando tiros contra o relógio da torre. Esse relógio, que retém a ideia de um tempo que para, que imutabiliza, que permanece, é o alvo simbólico da supressão dessa noção de tempo: acontecimento que modifica toda a estrutura do tempo, já que engendra outra estrutura, no caso revolucionário, relacional e, se Benjamim é suficientemente coerente com sua teoria, essa estrutura é em si mesma cambiante e propensa a constituir-se em outras totalmente distintas.

Também,emLuhmann,otempoéessefeixedeacontecimentossingulares, em que estes remetem aos conteúdos de sentido de outros acontecimentos anteriores, mas que possibilitam a autoprodução (autopoiesis) de estruturas de qualquer modo submetidas ao fluxo do tempo. Esse excedente semântico é resultante do processo evolutivo da sociedade moderna, a qual tornou cada vez mais à disposição uma explosão de informação, de conhecimentos técnicos e científicos, de transmissão e produção do saber de toda natureza. Esse mundo, em que as possibilidades de escolhas de sentido das experiências são infinitas e a acessibilidade a estas é cada vez maior, não nos induz, alerta-nos Luhmann (2005), a repetir o equívoco dos iluministas, segundo o qual o aumento na quantidade de saberes e sua democratização tornariam, consequentemente, o mundo mais transparente e as decisóes humanas mais racionais e acertadas. Ao contrário, essa abertura sem precedentes do mundo hodierno gerou um mundo altamente complexo e contingente. 
O segundo nível de problema para a teoria dos sistemas é a redução da complexidade do mundo. A bem da verdade, esta é a função ${ }^{18}$, por excelência, dos sistemas, pois, se o mundo não é um sistema ${ }^{19}$ - porque não existe fronteira a partir da qual possa ser delimitado -, e sim a "pressão da complexidade", terreno das contingências e da negatividade, os sistemas se autodefinem exatamente pela atualização sempre recorrente de redução da complexidade. Reduzir, aqui, está longe de qualquer noção hegeliana de superação em uma síntese completa e definitiva - ainda que o próprio Luhmann reconheça que a teoria dos sistemas mantenha relaçôes de proximidade conceitual com a teoria do sistema de Hegel -, porém, ao contrário, trata-se de preencher o tempo (os acontecimentos) com conteúdos pré-determinados por regras (remissóes de sentido) que limitem a contingência absoluta do acontecer, dando-lhe alguma regularidade mediante a função de decidir dentre a variabilidade de possibilidades de ação. Para melhor explicitar a autoconstrução da unidade sistêmica ou a unidade do mundo, recortei três passagens dos "Sistemas Sociais":

Sem surpresa [todo acontecimento é novo] não haveria formação de estrutura precisamente porque não haveria nada para relacionar. $\mathrm{O}$ novo, não obstante, não o é de todo; dado que constitui horizontes temporais próprios do passado (para ele) e do futuro (para ele), que é remetido ao contínuo do tempo. Desta maneira, este componente de surpresa se adere a estrutura e é tratado como se fosse esperada.

[...] Então, a decisão atualiza a autoreferência da ação que se realiza mediante as expectativas, isto é, que no sentido da ação está contida uma expectativa. Se para isso se necessite de consciência está pressuposto, porém é uma condição, não um rasgo característico da própria decisão. A decisão não é um estado de consciência, mas uma estrutura significativa.

[...] Faz-se necessário esclarecer que se trata de uma decisão porque a eleição é tratada como contingência e as ações sucessivas são motivadas por esta contingência. [...] Antes da decisão existe, portanto, a diferença das alternativas. [...] Das formas da contingência, a contingência aberta e o haver-existido-outra-possibilidade fora a decisão tomada, se encontram nessa unidade. (LUHMANN, 1998, p. 264, 270, 271).

18 “Os sistemas sociais têm por função a apreensão e a redução da complexidade. Servem como mediação entre a extrema complexidade do mundo e a capacidade muito menor, dificilmente alterável por razốes antropológicas, do homem para a elaboração consciente da vivência” (LUHMANN, 2005, p.80).

19 "O mundo não pode apreender-se como sistema, porque não tem nenhum 'fora', frente ao qual ele se delimite" (LUHMANN, 2005, p.76). 
Bem ao estilo weberiano de pensar o pluralismo valorativo e sua respectiva autonomia de sentido: "[...] uma coisa pode ser bela não só no aspecto no qual não é boa, mas antes nesse aspecto mesmo. [...] Uma coisa pode ser verdade, embora não seja nem bela nem sagrada nem boa. [...] Pode ser verdadeira precisamente nesses aspectos" (WEBER, 1982, p.174-5). Luhmann entende que os sistemas operam o tempo todo com a função de decidir entre infinitas possibilidades de orientação dos acontecimentos com base em "fronteiras semânticas" entre sistemas estruturadas no tempo. Isto é, cada sistema opera a decisão dos possíveis e reduz a complexidade do mundo, com base em sua referência de sentido que lhe é específica. Por exemplo: uma mesma situação, ou elemento dessa situação, pode ser analisada a partir da perspectiva particular de cada sistema que opera a decisão com base em códigos específicos previamente delimitados. Nesse sentido, cada operação de decisão realizada elimina as outras possibilidades, inclusive restringe as futuras, na medida em que forma uma rede de encadeamento de acontecimentos. Isso de algum modo acontece porque os sistemas acumulam informação ou comunicação, como é o caso do sistema psíquico, que, em função de seu caráter autopoiético e semanticamente autorreferente, remete ao acúmulo de informação deixado pelas operaçóes anteriormente efetivadas.

Não é correto pensar, todavia, que, para Luhmann, os sistemas se constituem em entidades fechadas nelas mesmas, sem correspondências semânticas recíprocas, tal como fossem peças compartimentalizadas, executando cada um, à sua maneira e sem correlação, a sua tarefa; paradoxalmente, se os sistemas são constitutivos de acontecimentos, se se autoconstroem sob o impacto permanente da complexidade do mundo, a inter-relação e as dependências semânticas recíprocas lhes são igualmente constitutivas.

Essa estruturação dos sistemas em "autorreferência" e "heterorreferência" pressupóe, enquanto referência compartilhada, o mundo como horizonte de sentido. E é com base nessa estruturação que é possível, para os sistemas que operam com sentido, ordenar os acontecimentos e engendrar algum nível de unidade diante do fluxo temporal e da infinitude de possibilidades eletivas. Nesse caso, opera-se a redução da complexidade e a formulação da unidade do ambiente mundo. Com uma escrita clara e direta, Luhmann assevera:

Portanto, nenhum sistema constituído por sentido foge da plenitude de sentido de todos os processos. O sentido remete a um sentido posterior. $\mathrm{O}$ fechamento circular desta remissão aparece em sua unidade como horizonte último de todo o sentido, como mundo, o qual. Por conseguinte, tem a mesma inevitabilidade e inegabilidade do sentido. [...] Por conseguinte, 
partimos de descrição fenomenológica das experiências de sentido e do nexo constitutivo sentido/mundo, porém não fundamos essa descrição na pré-existência de um sujeito extramundano (de que todo mundo sabe que existe como consciência), mas a concebemos como uma descrição do mundo no mundo. [...] A unidade da constituição plena de sentido (a constituição mundana do mundo do sentido) se articula mediante a descrição fenomenológica como diferença e pode servir nessa forma para ganhar informação. (LUHMANN, 1998, p.85-86).

Para um homem que, desde Freud, "[...] não é mais senhor em sua própria casa”, que não domina mais sua constituição psíquica, parece, com Luhmann, sofrer mais um duro golpe, à proporção que também não é mais constituído dos poderes de construção e dissolução das estruturas sociais e muito menos da capacidade de formulação de unidade ontológica do mundo. No limite, os homens ou "[...] as pessoas pertencem ao ambiente dos sistemas sociais" (LUHMANN, 1998, p.173). "Os sistemas sociais não constam de sistemas psíquicos e muito menos de seres humanos corporificados” (p. 236).

Essa concepção luhmanniana de mundo e de sociedade caracteriza, enfaticamente, a postura de um pensador cônscio da alta complexidade do mundo e da pressão dessa complexidade sobre os sistemas sociais e sobre o homem moderno. Na pressuposição de que o mundo, como horizonte de sentido, possa ser experimentado em cada situação singular, tal concepção opera com o conceito de mundo como "acêntrico"; a noção de sociedades sem pessoas implica a recusa de quaisquer tipos de humanismos e de qualquer modalidade de filosofia do sujeito; na formulação de sistemas autopoiéticos e autorreferentes, abandona uma suposta ordem previamente dada, na acepção de mundo como totalidade dos acontecimentos e de sentidos, enfrenta a contingência e a complexidade como insuperáveis, mas não como incontornáveis.

Por todos esses feitos teóricos, Luhmann define-se como um cientista antimetafísico e antifilosófico, por excelência, ainda que coloque como um dos problemas fundamentais para a teoria dos sistemas a compreensão da unidade do mundo, como se restassem resquícios da presença - que o próprio Luhmann reconhece - da ontologia husserliana. Entendemos que uma sociedade e uma teoria não podem se sustentar sem pressupor que, se "o início é a diferença e não a identidade", em algum momento, identidades móveis - porque superadas por outras - são construídas pelas estruturas internas 
dos próprios sistemas. Contudo, a pressuposição de unidade última remete à ideia de fundamento com fundo, e fundo ontológico em última instância, que sirva de "alento" ao homem desontologizado, descentralizado e destituído de seus poderes infinitos de criação dos tempos hodiernos. Esse é o elemento fundamental da teoria dos sistemas que mais aproxima Luhmann - do que efetivamente o afasta - dos engajamentos metafísicos husserlianos.

Dessa maneira, podemos, a despeito das próprias intenções de Luhmann, inseri-lo em um debate sociológico e filosófico em fins do século XIX e início do século XX, no qual se discute o tema da filosofia da cultura e mais especificamente da tragédia da cultura moderna. No primeiro caso, tratase, em sentido mais abrangente, da situação peculiar com a qual se depara o homem moderno diante do processo de racionalização moderno-ocidental; no segundo, em sentido mais específico, da posição analiticamente valorativa dessa situação. Poder-se-ia citar diversos autores em ambos os casos, porém, destaco dois pensadores entre esses séculos que são emblemáticos de uma análise trágica da cultura: Weber e Simmel; em Luhmann, é possível ler sua análise sobre a pressão da complexidade do mundo sobre os sistemas e sobre, indiretamente, o homem: a pressão das decisóes em que o mundo comparece como horizonte de referência de sentido.

Também Weber, com insuperáveis diferenças em relação à Luhmann, analisa o mundo moderno como um mundo de alta complexidade racional: diluição de unidades de sentido e emergência do politeísmo de valores, cuja constituição história da subjetividade do indivíduo moderno é fazer escolhas, ou seja, tornar-se um "sujeito" de liberdade, mas, ou por isso mesmo, irremediavelmente sozinho diante da tarefa de decidir-se acerca dos sentidos da sua conduta. Duas noçóes importantes decorrem disso: para Weber, a racionalidade torna possível a ação livre e seu conteúdo de sentido pode ser permanentemente inventado e reinventado. No entanto, esse indivíduo, já para um Weber pessimista e trágico, encontra-se em uma situação de "tempo desancorado", despida de quaisquer referências ontológicas, por conseguinte, torna-se presa fácil de si mesmo: aprisiona-se em estruturas normativas ou ordens sociais. Simmel leva às últimas consequências a crítica da cultura moderna, uma vez que não parece disposto a reconhecer nenhum momento de vigência mínima de liberdade, como o faz Weber; ao contrário, acredita que toda a emergência e atualização do processo de racionalização carrega sua negação: a autonomização das formaçóes objetivas e estruturação de padróes 
de vida ou equalização de estilos que impedem a realização das possibilidades últimas e das qualidades incomparáveis da individualidade livre.

Essas questôes - autonomia da ação $\mathrm{x}$ ordens sociais - que tanto afligiam a Weber e Simmel não são colocadas por Luhmann como problemas para sua teoria, muito pelo contrário. A pressuposição de que sistemas sociais (registro semelhante às ordens ou formaçôes sociais) possam ser construídos é condição sine qua non para a redução da intensa complexidade e contingência do mundo moderno. É possível sugerir que, na medida em que lida com temas dessa natureza (complexidade, decisão, remissão de sentido etc.), Luhmann se movimenta no âmbito de uma análise da cultura moderna, porém, nem de longe sugere que um dos principais resultados dessa cultura, a formação de estruturas sistêmicas, sejam ou devam ser negativamente avaliados a partir da perspectiva de todos os sistemas, como o fazem Weber e Simmel. A teoria dos sistemas de Luhmann (1998, p.173) parece desejar bloquear qualquer alusão valorativa, pois se trata, em última instância, da tarefa científica de descrever o mundo no mundo, despojada de quaisquer elementos metafísicos (LUHMANN, 1998, p.111).

Não é possível aqui defender as assertivas de um em detrimento de outros e vice-versa, quanto à caracterização da relação entre cultura moderna e estruturas sistêmicas (ordens sociais), muito menos cair no lugar comum das avaliações inconsequentes, em que um é conservador e os outros críticos "morais" da sociedade sistêmica. Não se trata disso.

Para encerrar, quero apenas sugerir que os rasgos essenciais da teoria dos sistemas de Luhmann lembram a perspectiva habermasiana de separaçáo da sociedade em duas vias de ação: a sistêmica, caracterizada por açóes orientadas para a dominação efetiva da natureza e para a organizaçáo funcional da sociedade; e ação comunicativa, cuja base seriam os recursos disponíveis no mundo da vida. Habermas faz uma clara aposta no teor de racionalidade valorativa contida no paradigma comunicativo, a expensas da racionalidade puramente instrumental do paradigma sistêmico. Se este se mantivesse em seu lugar de origem, ou seja, em sua lógica própria, possivelmente náo seria alvo das críticas de Habermas, o qual se ressente de sua invasão sobre o mundo da vida (fenômeno moderno de colonização da razão comunicativa).

Esse tipo de problema não preocupa Luhmann, em princípio, porque rejeita, em qualquer formato, o paradigma da ação social, mas principalmente porque elege como ponto de partida o conceito de sociedade como constituída 
de sistemas. E, quando define sistemas na sua diferenciação com seu ambiente (com o mundo), bem como expulsa os homens de seus domínios e recusa, por conseguinte, um mundo da vida como ferramenta recursiva e, por fim, constitui quase uma "técnica" de decisão entre possibilidades como redução da complexidade do mundo, parece-nos que se decide pelo tipo de racionalidade que Habermas exclui para uma via ontologicamente "inferior": a racionalidade sistêmica-instrumental. No entanto, sua análise depurada do problema da complexidade do mundo e todos os conceitos que mobiliza para formular uma resposta dentre outras tantas ${ }^{20}$ mostram uma plausibilidade desconcertante, quando referida ao mundo contemporâneo.

\section{RICHARD RORTY E SEU PROJETO DE UTOPIA LIBERAL}

Tal é o teor descentralizador, anti-humanista, desontologizante e intensificador do tema da diferença e da contingência da teoria luhmaniana que, exatamente por isso, poderia figurar entre os ironistas analisados por Richard Rorty.

A questão é: por que Luhmann, em determinados aspectos, poderia ser incluído na lista rortyana de autores ironistas? Não seria um contrassenso pressupor que o pensador da teoria dos sistemas ficaria confortável entre Heidegger, Nietzsche, Derrida, Wittgenstein e o próprio Rorty? Para responder a essas questóes, é preciso fazer duas importantes ressalvas. A primeira é que o próprio Luhmann, em alguns de seus textos, reconhece a influência positiva de Derrida sobre a sua teoria da comunicação; Husserl e sua fenomenologia comparecem repetidas vezes como seu interlocutor privilegiado, e uma análise comparativa entre sua concepção de reduçáo da complexidade de mundo e o problema da decisão do Dasein heideggeriano seria perfeitamente plausível; além disso, sua prerrogativa epistemológica de que o conhecimento científico é construído, que está limitado à "autodescrição do mundo no mundo", ou seja, apenas as descriçóes podem ser verdadeiras ou falsas, mas não o mundo, e que a linguagem comunicativa é uma ferramenta ou uma operaçáo que não está dada no mundo como algo para ser simplesmente descoberta - enfim, tudo isso o aproxima, em larga medida, de Wittgenstein.

A segunda ressalva - antes mesmo de analisar o conceito rortyano de ironista liberal - sugere que se abandone, para que Luhmann possa ser nele

20 "A teoria dos sistemas [...] não reclama exclusividade. Não sustenta ser a única teoria sociológica correta" (LUHMANN, 1998, p.15). 
incluído e para que pensadores como Derrida, Foucault e Wittgenstein (também Luhmann) sejam preservados, a noção de liberal do ironista liberal, por diversas razôes. A principal dentre elas é que, segundo Rorty, "[...] liberais são as pessoas que consideram a crueldade a pior coisa que fazemos" (2007, p.18) e, enquanto tais, pressupóem a possibilidade de convivência da autocriaçáo privada e da solidariedade pública como base de uma utopia liberal. Esses teóricos podem ser lidos como ironistas e não como ironistas liberais, como enfaticamente afirma Rorty; no entanto, não exatamente porque suas teorias são "inúteis" na esfera política - como se suas teorias, mesmo a despeito de si mesmas, não pudessem ser levadas a reboque de uma teoria política qualquer -, mas talvez porque seus autores quiseram evitar o equívoco e a incoerência de um projeto político utópico, sob as bases de um pensamento metafórico, contingente e pós-metafísico. Como pensar um projeto utópico, portanto, "para o ainda não", quando se pressupôe que o campo das açóes tanto individuais quanto coletivas é cravejado por clivagens e contingências? Quando a esfera individual, sua preferência valorativa pelo liberalismo, adentra o campo público como o projeto, por excelência, a ser construído? A constituição de uma unidade, de uma estruturação ou de um campo de refluxo identitário mínimo emerge, de forma intencional ou não, na perspectiva desses teóricos da contingência e da autopoiésis. No caso de Rorty, especificamente, parece ser uma "bemintencionada" ampliação do horizonte limitado de seus interlocutores ironistas. O termo "ironista” é utilizado por Rorty para "[...] designar o tipo de pessoa que enfrenta a contingência de suas convicçóes e seus desejos mais centrais - alguém suficientemente historicista e nominalista que abandonara a ideia de que essas convicçóes e esses desejos centrais remontam a algo fora do alcance do tempo e do acaso" (RORTY, 2007, p.18).

Antes de ser "bem-intencionado", Rorty é sobremaneira um teórico importante para a reflexão filosófica e sociológica contemporânea, ao deslindar criticamente o que ele chama de cânone Platão-Kant da tradição ocidental: a contingência foi tradicionalmente pensada em oposiçáo ao universal, essencial e intrínseco. O pano de fundo dessa oposição é o pensar metafísico, através de dicotomias rígidas entre absoluto x relativo, construção x criação, contingente $\mathrm{x}$ universal, enfim, o modus operandi da tradição que tem sido alvo de duras críticas desde Nietzsche. $\mathrm{O}$ novo da concepção rortyana é teorizar sobre a contingência e sobre o acaso, sem a tentativa, no plano da filosofia, de escapar dela na perspectiva de uma transcendência. Para isso, mobiliza a "porção" contingente do pensamento de Kant a Heidegger e Wittgenstein. 
Em um primeiro momento, examina a contingência na linguagem a partir de seu primeiro grande golpe que a concepção de verdade científica, como intrínseca à realidade e passível de ser descoberta pelo intelecto humano, sofreu com Kant e Hegel: o conhecimento científico é construído e, sendo tal, não existe enquanto uma verdade ontológica. Afirma Rorty: "O mundo existe, mas não as descriçôes do mundo" (2007, p.28). O segundo grande golpe seria aquele operado pela filosofia da linguagem (Wittgenstein e Davidson), que abandona a noçáo de linguagem como representaçáo do real (ou, como denomina o próprio Rorty: espelho da natureza), isto é, a linguagem era considerada a expressão da verdade do mundo: mera mediação entre o eu conhecedor e o mundo. Para Rorty, ao contrário, não existe a linguagem, mas as linguagens que são construídas junto com as verdades que são "propriedades de entidades linguísticas"; por conseguinte, verdades são construídas quando linguagens (frases) são construídas.

Entretanto, isso não significa afirmar que as verdades produzidas são menos ou mais verdadeiras, porque deixaram de estar ontologicamente acopladas à realidade. Não é um relativismo inconsequente que deriva dessa "nova filosofia", adverte-nos Rorty, porém, uma recusa em prosseguir na disputa para saber quem tem o controle sobre a verdade: "O problema dos argumentos contrários ao uso de um vocabulário conhecido e consagrado pelo tempo é que se espera que eles sejam formulados nesse mesmo vocabulário" (RORTY, 2007, p.34). Com isso, Rorty está fundando algo totalmente novo, tanto na esfera filosófica, com a "filosofia interessante" (RORTY, 2007), quanto na científica, com a ciência revolucionária, e na política, com a política utópica. $\mathrm{O}$ argumento aqui em jogo é simples e direto: pressupóe-se uma disposiçãoo para enfrentar as contingências de suas convicçóes, para reconhecer as convençôes linguísticas (ser nominalista e historicista), no limite, disposição de ironista para descrever as coisas de modos novos.

A atuação do ironista é tão demarcadora de uma ação revolucionária que Rorty, com base na concepção de Davidson de linguagem como metáfora, flexibiliza, inclusive, a noção de fato e significado de Wittgenstein, para evitar que sejam confundidos com uma concepção de linguagem como uma entidade que medeia a relação entre o eu e a realidade ou como "algo" que se tem em comum, a língua com seus jogos e suas ferramentas próprias. Com a ideia de que as metáforas (as descriçôes novas) desaparecem quando são literalizadas (tornam-se significados), significa dizer que o que se tem são teorias contingentes sempre, portanto, passíveis de serem refeitas. Nessa medida, o 
filósofo da "filosofia interessante" radicaliza a consciência wittgensteiniana e davidsoniana da contingência da linguagem, escrevendo como se suas palavras fossem metáforas que "produzem efeito no interlocutor":

\begin{abstract}
Na visão que sugiro a afirmação de que uma doutrina filosófica "adequada" deve dar margem a nossas intuiçôes é um lema reacionário, que se esquiva da questáo em exame. Pois é essencial em minha visão que não temos nenhuma consciência pré-linguística a que a linguagem precise adequarse, nenhum senso profundo de como as coisas são, o qual seja dever dos filósofos explicitar na linguagem. $\mathrm{O}$ que se descreve como essa consciência é a simples disposiçâo de usar a linguagem de nossos ancestrais, de cultuar os cadáveres de suas metáforas. A menos que soframos do que Derrida chama de "nostalgia heideggeriana", não pensaremos em nossas "intuiçôes" como mais do que banalidades, mais do que o uso habitual de um certo repertório de termos, mais do que velhas ferramentas que ainda não têm substitutos (RORTY, 2007, p.54).
\end{abstract}

Essa contingência absoluta da linguagem assume ares ainda mais contundentes, na sua análise da contingência da identidade e o inconsciente freudiano. A premissa moral básica, desde a tradição metafísica até Kant, sustenta que o homem é dividido entre a razão (consciência-racional) e paixôes (instintos-irracionais) e que a condição para sua moralidade é o controle absoluto de suas paixóes pela razão. Entretanto, Freud desestabiliza esse "homem duplex", com a afirmação de que sua mente é uma estrutura de configuraçôes extremamente complexas, constituída por instâncias conscientes e inconscientes (ego e id), autônomas e, muitas vezes, incompatíveis entre si. Por conseguinte, ao invés de um homem partido, temos um homem "total", no qual se instala uma luta difícil de afirmar que o ego é sempre "senhor em sua própria casa”, isto é, que assume o controle diante de informaçóes inusitadas, de situaçóes que os desejos e afecçôes do inconsciente lhe impóem de maneira incontrolável. A função da psicanálise, ensina-nos Freud, é mostrar os limites do ego, lembrando-lhe que ele convive com outra instância (o inconsciente) igualmente constitutiva de poder, não apenas de subversão de toda ordem, mas de poderes criativos e intelectivos. Cito duas passagens: a primeira, de Freud, na qual nos revela o alcance de suas descobertas, e a segunda, de Rorty, que procura reter a configuração contingente do indivíduo.

É assim que a psicanálise tem procurado educar o ego. Essas duas descobertas - a de que a vida dos nossos instintos sexuais não pode ser inteiramente domada, e a de que os processos mentais são, em si, inconscientes, e só atingem o ego e se submetem ao seu controle por meio de percepçóes 
incompletas e de pouca confiança -, essas duas descobertas equivalem, contudo, à afirmação de que o ego não é o senhor da sua própria casa. Juntas, representam o terceiro golpe no amor próprio do homem, o que posso chamar de golpe psicológico (FREUD, 1969, p.178).

[...] Freud desarticula todas as distinçóes tradicionais entre o superior e o inferior, o essencial e o acidental, o central e o periférico. Deixa-nos um eu que é uma trama de contingências, e não um sistema ao menos potencialmente bem ordenado de faculdades (RORTY, 2007, p.71).

Rorty parece se deleitar com a desdivinização do eu operada por Freud. Sendo o indivíduo, visto sob esse paradigma, constituído por uma rede diversificada de crenças e desejos, dotado, por consequência, de um psiquismo peculiar e em luta interna constante consigo mesmo, torna-se indefensável a ideia de centralidade do "eu" e de uma suposta coerência interna frente às diferentes instâncias. E mais, esse inconsciente constituidor da subjetividade humana (junto ao consciente) também é investido de extraordinária inteligência e sofisticação, pois, como explica toda sua sutileza e destreza na tarefa de driblar a consciência e de se impor?

De fato, há de se reconhecer, fazendo eco a Rorty, que Freud não exagerou na sua autoimputação de operador do "terceiro golpe no narcisismo universal dos homens" e nem quando afirmou ser este o mais importante frente aos demais (o primeiro, cosmológico; o segundo, biológico). De fato, as implicaçóes daí decorrentes foram e parecem ainda ser inúmeras. Rorty recorta uma dessas implicaçóes, quando acredita que a psicanálise freudiana foi responsável por outro modo de lidar com o processo de conhecimento das psiques e de suas idiossincrasias. Partir do pressuposto de que o indivíduo é contingente suscitou em Freud a elaboração do método de autoconhecimento do indivíduo, em que este reconstitui sua história, na tentativa de familiarizarse com a rede peculiar de crenças e desejos que o animam e o configuram, engendrando uma autoimagem de si, toda ela particular e contingenciada. Disso resulta que náo existe uma identidade pré-fixada e universalmente partilhada, ao contrário, é o produto contingente e reformulável da autocriação do indivíduo.

Essas reflexôes freudianas servem de esteio para a discussão efetuada por Rorty sobre a distinção entre a ética privada da autocriação e a ética pública de acomodação mútua, éticas indiscutivelmente incompatíveis entre si. Isso 
porque compreender o indivíduo é compreender suas experiências particulares e seus caracteres específicos que o fizeram como tal, despindo-se da intenção de encontrar-se abrigado em uma natureza comum. As descriçóes que cada um faz de si mesmo não o remete, necessariamente, a nenhuma configuração comunitária, apenas revela sua autocompreensão por meio de um vocabulário parcialmente seu.

Segundo Rorty, este é o segredo de uma sociedade que vive sob a égide de um liberalismo recriado, caracterizado, sobretudo, pela criação ou autocriação de cidadanias condizentes com o seu caráter contingente, metafórico e antifundacionista, porque, se o progresso intelectual e o progresso político são obras dos acasos fortuitos e das literalizaçóes de metáforas, as ações que lhe deram forma são constituídas pelo mesmo material, ou seja, pela linguagem e pela conduta do ironista liberal. Por isso, os heróis de uma sociedade dessa natureza são os “[...] poetas fortes e o revolucionário utópico" aqueles que “[...] protestam contra os aspectos da sociedade que não são fiéis à sua própria autoimagem" (RORTY, 2007, p.115). Tais heróis ou tais ironistas não são Nietzsche, Heidegger e Wittgenstein, posto que, “[...] como filósofos públicos, eles são inúteis, na melhor das hipóteses, e perigosos, na pior delas” (p. 127).

Diante dessa evidente contradição (ironistas inúteis e sociedade liberal), deve-se esclarecer melhor o significado tanto de ironia liberal quanto de comunidade liberal. De acordo com Rorty, a sociedade liberal moderna está pautada na compreensão de que nossos valores sociais estão constantemente sendo refeitos, como parte indissociável do processo de criação de metáforas privadas. A figura do ironista distingue-se da figura do metafísico liberal, porque, ao contrário deste, não defende a existência de uma natureza comum a qual justifique ou responda pela dor dos semelhantes; apenas pretende redescrever o sofrimento alheio, a esperança e a solidariedade com base em um vocabulário contingente, que, por isso mesmo, não intenciona ser o mais verdadeiro e o mais universal. Mas a figura do ironista pensada por Rorty para compor sua utopia liberal não se limita a fazer redescrições privadas, porém, as amplia em torno de açóes públicas no sentido de diminuir a dor e o sofrimento dos outros. Desse grupo, Rorty exclui as figuras "clássicas" da ironia: Hegel, Heidegger, Nietzsche:

A Europa, o Espírito e o Ser não são apenas acúmulos de contingências, produtos de encontros ao acaso - o tipo de coisa que Proust sabia ser. Essa invenção de um herói maior do que o eu, em termos de cuja carreira eles definem o objetivo de sua própria carreira, é o que diferencia Hegel, Nietzsche e Heidegger de Proust, e o que faz deles teóricos, e não 
romancistas: pessoas que olham para algo grande, em vez de construírem algo pequeno. Embora sejam ironistas autênticos, e não metafísicos, esses três autores ainda não são nominalistas plenamente desenvolvidos, porque não se contentam em dispor coisas pequenas. Querem também descrever uma coisa grande. (RORTY, 2007, p.176).

Essa metáfora conceitual "coisa grande" remete à ideia de que, conforme Rorty, o trabalho dos ironistas mantém uma relação com o passado da teoria e não com a realidade, e esta o induz a buscar meios de superar as conclusóes de seus predecessores. Ao contrário de ironistas como Proust, as contingências apenas têm sentido no processo de rememoração e, portanto, de redescrição sempre remetida a situaçóes singulares e reais; nada de uma versão romanceada da posição reativa de quem errou antes dele, antes da inauguração do absolutamente novo do Em Busca do Tempo Perdido. Por isso, no entender de Rorty, ironistas - como Proust e outros tantos poetas, romancistas e jornalistas - são fundamentais para produzir uma espécie de "cultura poetizada" ${ }^{21}$, pois têm o desprendimento teorizante necessário para ajudar-nos a ver o sofrimento, a dor e a humilhaçáo humanos, em situaçóes nunca dantes vistas ou percebidas, porque apenas os ironistas liberais acreditam que o que une a todos é a suscetibilidade à dor dos outros. Isto é, tudo que o ironista liberal quer evitar, avisa-nos Rorty, é a crueldade.

Esse raciocínio de Rorty está profundamente enraizado com sua compreensão de contingência da linguagem e contingência do indivíduo, no sentido de que não há uma linguagem única prevalecente e nem uma identidade de sujeito que podemos apontar como referência básica para a definição das justificativas normativas de como "agir corretamente" ou "conforme a verdade" para todos. Nesse sentido, a ironia liberal expressa uma liberação de nossa capacidade imaginativa para enxergar os estranhos como parceiros do sofrimento. $\mathrm{Na}$ escrita rortyana, "[a] solidariedade não é descoberta pela reflexão, mas sim criada. É criada com o aumento da nossa sensibilidade aos pormenores específicos da dor e da humilhaçâo de outros tipos não familiares de pessoas" (RORTY, 2007, p.118).

Os heróis da sociedade liberal de Rorty, por conseguinte, são aqueles "poetas fortes" e "revolucionários utópicos". Todavia, estes não devem ser

21 "Precisamos de uma redescriçáo do liberalismo como esperança de que a cultura como um todo possa ser 'poetizada', e náo como a esperança iluminista de que ela possa ser 'racionalizada' ou "cientizada”' (RORTY, 2007, p.103). 
apenas os personagens de romances ou figuras poetizadas ou jornalistas sensíveis - se assim fosse, Rorty se manteria incólume da acusação de produzir seu vocabulário final. $\mathrm{Na}$ verdade, são amostragens de como devem ser, e, efetivamente, são todos os homens que vivem sob a vigência da utopia liberal, já que todos os humanos desfrutam a mesma capacidade de autocriação, autodescrição e de suscetibilidade à dor e humilhação.

Em minha utopia, a solidariedade humana seria vista não como um fato a ser reconhecido, mediante a eliminação do "preconceito" ou o mergulho em profundezas antes ocultas, mas como objetivo a ser alcançado. E a ser alcançado não pela indagação, mas pela imaginação, pela capacidade imaginativa de ver pessoas estranhas como semelhantes sofredores. (RORTY, 2007, p.20).

Nesse sentido, se Rorty acusa - e com razão - Nietzsche, Heidegger e Foucault de terem cedido à pressão de construírem "uma coisa grande" ou um vocabulário final ou um projeto com dignidade metafísica, porque são ironistas presos aos limites da reflexão e à teoria, pode-se sustentar que seu projeto de utopia liberal não escapa com sucesso desse equívoco. Ora, se ser um ironista é duvidar dos conteúdos normativos que legitimam as açôes corretas e redescrever, continuadamente, suas imagens das coisas: ser plenamente um nominalista e um historicista, como os "heróis" da diferença e da contingência não conseguiram ser, como defender ideais de liberalismo como pautas básicas de uma sociedade do "nós" solidário e liberal - uma feliz utopia liberal? Por que toda fundamentação metafísica das teorias liberais e democráticas não são questionadas por Rorty? Que tipo de ironista - e ironista liberal - não redescreve as tensões entre ideais liberais e sociedades liberais reais? Que tipo de ironista, que leva às últimas consequências suas formulaçóes contingentes, pode pensar em uma utopia liberal, cuja característica é justamente ser projetivo e escapar das contingências do tempo e do espaço, existindo, por conseguinte, como recaída na metafísica? Uma resposta plausível para isso não é pressupor uma sociedade de poetas mortos e poetas vivos, em que "todos" compartilham a dor e humilhação e produzem redes de sentido desalojadas das gastas figuras da metafísica, tampouco pode se pautar uma sociedade na cisão entre autocriação privada e solidariedade pública, visto que as configuraçóes da autocriação (linguagem, por exemplo) são constituídas e estruturadas no registro público. 


\section{CONSIDERAÇÓES FINAIS}

Rorty, portanto, enfrenta as contingências do mundo contemporâneo, apostando no partilhamento da "retórica das democracias liberais" - a retórica do "um de nós", e não como "eles" - como a mais aceita e mais adequada em uma sociedade caracterizada pelo fim das metanarrativas e das condutas de moral absoluta. No entanto, a ironia da análise rortyana é que sua crítica e sua proposta se misturam num pragmatismo moral mal disfarçado, pois, se ironistas como Nietzsche, Heidegger - e incluímos Luhmann - são politicamente perigosos, porque suas teorias são "fórmulas vazias" que podem ser preenchidas com quaisquer conteúdos específicos, a teoria rortyana da comunidade liberal pode ser ainda mais perigosa, já que se apresenta como a mais "neutra" e antimetafísica dentre todas as teorias anteriores, porque enfrenta as contingências, as diferenças e as metáforas "metaestáveis", sendo, por isso, mesmo a mais adequada para realizar os valores da solidariedade e da aversão à crueldade e à humilhação.

Luhmann, ao contrário, levou até o fim a preocupação, abandonada por Rorty, de elaborar uma teoria antimetafísica e despida de um projeto normativo para a sociedade contemporânea. Sua teoria dos sistemas encarna perfeitamente esse vazio de conteúdo que Rorty denuncia, como também torna a crítica a ela dirigida inconsistente e até mesmo inviável, já que as operações comunicativas realizadas pelos sistemas para enfrentar a contingência do mundo excluem tudo que for externo ao sistema, ou seja, tudo que náo possa se tornar um mecanismo de manutenção da identidade dos sistemas face à complexidade do mundo: os incontornáveis sentidos ou possibilidades de ação, diversos valores e normas que contrastam entre si.

Assim, do ponto de vista da coerência e consistência interna da teoria dos sistemas, Luhmann, na comparação com a teoria do ironista liberal de Rorty, apresenta-se como aquele que, efetivamente, realizou a superação da metafísica, essencialmente nas dimensôes racionais, valorativas e sensíveis. Resta saber se, do ponto de vista da formulação de uma teoria coerente e consistente com a preocupação científica e filosófica com a vida em sociedade, Luhmann oferece uma teoria minimamente plausível. Adiantamos que, nessa comparação, ficamos com Rorty, que apostou numa prática de redescrição de si e do mundo, para a atualidade, na qual a dominação da identidade metafísica já não pode ser defendida sem se incorrer em universalismo fundamentalista. Se, de fato, vivemos sob o domínio da complexidade do mundo e da urgência em reduzila, por meio de mecanismos e operações meramente técnicas, esse domínio 
atualiza-se mediante lutas culturais, disputas de valores, divergências, consensos e dissensos políticos, como também por práticas cotidianas de criação de formas alternativas de existência, apreendidas inclusive em romances literários, tal como nos sugere Rorty, com base em sua leitura de Em busca do tempo perdido, de Proust. Podemos constatar isso recordando que as trajetórias individuais de algumas personagens de Proust podem ser lidas como figuras emblemáticas de indivíduos inscritos e descritos em determinados constrangimentos sociais, que, a despeito de seu caráter de orientação de vida inescapável, conseguem reorientar o curso de suas vidas, atualizando possibilidades que são aventadas por acontecimentos, acasos e situaçóes totalmente imprevistas. Em todos os sete volumes da obra romanesca de Proust, vemos o narrador empenhado em narrar a história de sua vida, da infância à idade adulta. Nesse processo, perpassa por vários lugares da França (Combray, Balbec, Paris), por diferentes épocas (pelo menos de 1878 a 1918), por conflitos amorosos (de natureza homo e heterossexuais), por espaços sociais de distinção (os salóes franceses, por exemplo), pela definição dos gostos artísticos e pela crítica de arte (música, pintura, teatro). E, nessa empreitada, recorre à sua memória do passado, mas não à pressuposição de uma memória linear, purificada, racional. Recorre, sim, àquela memória que soube definir e atualizar de maneira exemplar: a memória ${ }^{22}$ que escapa ao esforço racional e consciente e ressurge por intermédio de sensações, acontecimentos, de detalhes na rotina cotidiana, de imagens recriadas, e a memória involuntária que permitiu ao narrador proustiano recriar a sua trajetória de vida e de tantos indivíduospersonagens, com os quais manteve relaçóes de interdependência sociais.

Por fim, essa prática de rememoração, em que se vai ao passado a partir das contingências presentes, pode conduzir seus leitores à descoberta e redescoberta de sentimentos, emoçóes e valores que as sociedades vazias de sentido fizeram desaparecer do universo de ação individual e social. Acompanhar a descrição de trajetórias de dor, percalços, solidão pode despertar, no acompanhante, tanto a prática ética de se sentir no lugar do outro quanto a possibilidade de se reconhecer com a capacidade devida para refazer sua própria trajetória no mundo. Essas apostas, de qualquer maneira, indicamnos que a descrição do mundo como regido apenas por uma razão pura e por

${ }^{22}$ Escreve: "Na verdade, poderia responder, a quem me perguntasse, que Combray compreendia outras coisas mais e existia em outras horas. Mas como o que eu então recordasse me seria fornecido unicamente pela memória voluntária, a memória da inteligência, e como as informaçóes que ela nos dá sobre o passado não conservam nada deste, nunca me teria lembrado de pensar no restante Combray. Na verdade, tudo isso estaria morto para mim" (PROUST, 1998, p.48). 
procedimentos sistêmicos não se sustenta; que é perfeitamente coerente pensar em modos atuais de viver eticamente, ainda que no plano individual.

LEAL, Edilene Maria Carvalho. Niklas Luhmann and Richard Rorty: contingencies and inconsistencies. Trans/Form/Ação, Marília, v. 38, n. 1, p. 103-132, Jan./Abr., 2015.

\begin{abstract}
Rorty faces the contingencies of contemporary world by betting on the sharing of liberal democracies rhetorics as most fitted for a society characterized by the end of meta-narratives and absolute moral conducts. This bet clearly presents a moral pragmatism contrary to the ideas of Luhmann, who takes to its final consequences the project abandoned by Rorty of elaborating an antimetaphysics without a normative project for contemporary society. Luhmann's theory of systems faces the contingencies of the world by excluding all that is external to the system, that is, all that cannot be converted into a mechanism of the maintenance of the identity of systems in facing the complexity of the world.
\end{abstract}

KEYWORDS: Contingencies. Complexity. Liberal utopia.

\title{
REFERÊNCIAS
}

ARISTÓTELES. Metafisica: livro I. Porto Alegre: Globo, 1969.

BECHMANN, G.; STEHR, N. Niklas Luhmann. Tempo Social, São Paulo, v. 13, n. 2, p.185-200, novembro de 2001.

BENJAMIN, W. Charles Baudelaire: um lírico no auge do capitalismo. In: . Obras escolhidas III. Brasília: Brasiliense, 1989.

BORNHEIM, G. Sobre o estatuto da Razão. In: . A Crise da Razão. São Paulo: Companhia das Letras, 1996.

BRÜSEKE, F. A descoberta da contingência pela teoria social. Sociedade e Estado, v. 17, n.2, p. 283-308, jul./dez. 2002.

DELEUZE, G. Diferença e repetição. 2. ed. Rio de Janeiro: Graal, 2006. ._Proust et les signes. Paris: Quadrige/PUF, 2007.

DERRIDA, J. A Escritura e a diferença. Rio de Janeiro: Perspectiva, 2002. . Gramatologia_São Paulo: Perspectiva, 2006.

FOUCAULT, M. As Palavras e as coisas. São Paulo: Martins Fontes, 1999. . La Volonté de Savoir: droit de mort et pouvoir sur la vie. Paris: Gallimard, 2006. 
FREUD, S. Uma dificuldade no caminho da Psicanálise. In: Obras Completas. Rio de Janeiro: Imago, 1976. v. 17.

GRANGER, G.G. Por um conhecimento filosófico. Campinas, SP: Papirus, 1989.

HABERMAS, J. Acción comunicativa y razón sin transcendencia. Barcelona: Paidós, 2002. . Consciência moral e agir comunicativo. 2. ed. Rio de Janeiro: Tempo Brasileiro, 2003.

HEIDEGGER, M. Ser e tempo. Rio de Janeiro: Vozes, 1995. 2v.

HUSSERL, E. Meditaçôes Cartesianas. Lisboa: Rés, 1988.

LUHMANN, N. Observaciones de la modernidad: racionalidad y contigencia em la sociedad moderna. Buenos Aires: Paidós, 1997.

. Sistemas sociales: lineamentos para una teoría general. Barcelona: Anthropos, 1998. . Iluminismo Sociológico. Lisboa: FTC, 2005. v. 1.

. Risk: a sociological theory. New Jersey: Fourth Printing, 2008.

. Introdução à teoria dos sistemas. Rio de Janeiro: Vozes, 2009.

NIETZSCHE, F. Além do bem e do mal. São Paulo: Companhia das Letras, 1992.

. Genealogia da Moral. São Paulo: Companhia das Letras, 1998.

. A Gaia Ciência. São Paulo: Companhia das Letras, 2007.

PLATÃO. O Sofista. São Paulo: Abril Cultural, 1972. (Coleção Os Pensadores)

PROUST, M. A Fugitiva. In: . Em busca do tempo perdido. 7. ed. Rio de Janeiro: Globo, 1988a.

A Prisioneira. In: Em busca do tempo perdido. 7. ed. Rio de Janeiro: Globo, 1988b.

. À Sombra das raparigas em flor. In: Em busca do tempo perdido. $7 \cdot$ ed. Rio de Janeiro: Globo, 1988c.

. O Tempo Redescoberto. In: Em busca do tempo perdido. 13 ed. Rio de pJaneiro: Globo, 1998.

RORTY, R. Ensaios sobre Heidegger e outros. Rio de Janeiro: Relume Dumará, 1999.

. Filosofia, racionalidade, democracia. São Paulo: UNESP. 2005.

. Contingência, ironia e solidariedade. São Paulo: Martins Fontes, 2007.

Recebido em: 19/08/14

Aceito em: 21/10/14 